\title{
Association Between Oral Health Literacy and Number of Remaining Teeth Among the Thai Elderly: A Cross-Sectional Study
}

This article was published in the following Dove Press journal: Clinical, Cosmetic and Investigational Dentistry

\author{
Nithimar Sermsuti- \\ anuwat (iD) \\ Panat Piyakhunakorn ${ }^{2,3}$ \\ 'Faculty of Dentistry, Chulalongkorn \\ University, Bangkok, Thailand; ${ }^{2}$ Master of \\ Science Program in Geriatric Dentistry \\ and Special Patients Care (International \\ Program), Faculty of Dentistry, \\ Chulalongkorn University, Bangkok, \\ Thailand; ${ }^{3}$ Panare Hospital, Dental Public \\ Health Division, Pattani, Thailand
}

Correspondence: Nithimar Sermsutianuwat

Faculty of Dentistry, Chulalongkorn University, 34 Henri-Dunant Road,

Wangmai, Pathumwan, Bangkok, 10330 Thailand

Tel $+662218-9016$

Fax $+662218-9021$

Email nithimar.s@chula.ac.th
Purpose: Limited oral health literacy is associated with poor oral health status. This study aimed to determine the association between oral health literacy (OHL) and the number of remaining teeth (NRT) among Thailand's older population.

Patients and Methods: This cross-sectional study was conducted between July 1, 2020 and September 30, 2020 at the Subdistrict Health Promoting Hospitals in Panare, Pattani, Thailand. A total of 361 independent-living older adults, male and female, participated in the study. OHL data were obtained using the Thai version of Health Literacy in Dentistry (HeLD-Th) questionnaire. Trained interviewers performed face-to-face interviews for oral health-related behavior information. The NRT was collected through intraoral examination by a trained examiner. Data were analyzed using SPSS version 22. Mann-Whitney $U$-tests, chi-square tests, and binary logistic regression analysis were performed. A multivariate logistic regression model was developed to test associations between OHL and NRT and other potential covariates. All analyses were two-sided with a $95 \%$ confidence interval.

Results: There were significant associations between limited OHL and fewer than 20 remaining teeth (odds ratio $[\mathrm{OR}]=1.986, \mathrm{P}=0.018)$, older age $(\mathrm{OR}=1.743, \mathrm{P}=0.023)$, and lower educational levels $(\mathrm{OR}=2.365, \mathrm{P}=0.007)$.

Conclusion: The significance of this evidence is that OHL influences NRT among older Thai people who have lower education levels. Therefore, OHL intervention is an essential strategy for better oral health-related behaviors to reduce tooth loss and to improve the oral health status of Thai older adults.

Keywords: oral health, geriatrics, oral health literacy, number of remaining teeth

\section{Introduction}

Oral health literacy (OHL) is a critical concern directly related to personal encouragement, oral health-related understanding, and the capability to use oral health evidence for making a reasonable decision on oral health care promotion, prevention, and utilization. Moreover, OHL is used to assess people's ability to acquire, to process, and to understand essential oral health information, including the necessary resources to complete appropriate oral health care. ${ }^{1}$ OHL refers to a communitybased asset that needs to be strengthened by community involvement and dental professionals' concerns at the population level. ${ }^{2,3}$

Previous evidence demonstrated that low OHL was associated with suffering oral health $^{4-6}$ and improper oral health-related behaviors, ${ }^{7-9}$ including dissatisfaction with oral health. ${ }^{10}$ These factors result in lower oral health-related quality of 
life. ${ }^{2,3,11}$ A few studies have indicated an association between OHL and periodontal disease in adults; those with low OHL were more likely to have severe periodontitis, higher plaque scores, and severe tooth loss. ${ }^{12,13}$

The number of remaining teeth (NRT) is a determinant of oral health and general health in various aspects, such as functional ability, physical symptoms, social functioning, healthy perceptions, and quality of life. ${ }^{14-18}$ In Thailand, the remaining at least 20 residual teeth among the older population are an oral health indicator. ${ }^{16}$ However, the prevalence of tooth loss in elderly Thai individuals persists. Approximately, $60.6 \%$ of the Thai population aged 60-74 has fewer than 20 remaining teeth, and $77.6 \%$ of the elderly Thai population aged $80-85 .{ }^{16}$ Previous studies have suggested that increasing OHL is a very successful strategy to minimize oral health iniquity, to bring better oral health status, to increase NRT, and to improve quality of life..$^{19,20}$

The majority of OHL research has been conducted in the general adult population..$^{2-7,12,13}$ There is a lack of dental evidence that focuses on OHL and NRT among Thai elderly individuals. Therefore, this research aimed to evaluate the relationship between OHL and NRT among the older population in Thailand and to prove that they may be related. This initial study will provide essential information for planning OHL education interventions to prevent oral diseases and tooth loss in Pattani Province, one of Thailand's three southernmost provinces.

\section{Patients and Methods Study Design and Location}

This community-based cross-sectional study was conducted in the Panare district, Pattani Province, Thailand between July 1, 2020, and September 30, 2020.

\section{Ethical Approval}

The research protocol was approved by the Ethics Review Committee for Research Involving Human Participants, Health Sciences Group, Chulalongkorn University, Thailand (COA No 058/2020). The study was performed in accordance with the Declaration of Helsinki. Each participant signed a written informed-consent form before participation.

\section{Participants}

The sample size was calculated. We analyzed the proportion value based on a previous study, ${ }^{21}$ in which $52.5 \%$ of the study participants presented OHL levels higher than the mean. Consequently, the sample size was 361 individuals, assuming a two-sided test and a significance level of less than 0.05 with a power of $80 \%$. A convenience sample of older adults living in the Panare community were encouraged to take part in the research. The inclusion criteria were as follows: (1) males and females over 60 years of age; (2) living independently per the Thai Barthel Activities of Daily Living (ADL) index ${ }^{22}$ and (3) capable of responding to the questionnaire via a Thai interview. The exclusion criteria were (1) having speech disorders, (2) having a severe chronic disease, or (3) having a disability condition.

\section{Independent Variables and Outcome Variable Independent Variables}

Activities of Daily Living (ADL), Oral health literacy (OHL), and sociodemographic and oral health-related behavior variables.

Trained reviewers used the Thai Barthel ADL index ${ }^{22}$ to evaluate the capability of daily living activities, including grooming, eating, dressing, transfer, mobility, use of stairs, bathing, use of toilets, and bowel and bladder functions. The sum of scores from 0 to 20 was classified into three categories as follows: (1) the dependent group with 0 to 4 ADL scores; (2) the most-likely-independent group with 5 to 11 ADL scores; and (3) the independent group with $\geq 12$ ADL scores. Higher ADL scores were indicated as independent living. ${ }^{23}$ We encouraged elderly Thai individuals with scores $\geq 12$ to enroll in this study.

The trained interviewers collected OHL data using the Thai version of the Health Literacy in Dentistry questionnaire (HeLD-Th). The HeLD-Th comprises 14 questions with a total possible sum of scores of 56 , and a higher score on the HeLD-Th represents a higher degree of OHL. ${ }^{21}$ The HeLD-Th comprises the following subscales: Communication, Understanding, Receptivity, Support, Utilization, Economic Barriers, and Access; the HeLDTh was validated in the Thai language and had favorable psychometric properties for measuring OHL among Thai adults with mild-to-moderate disabilities. ${ }^{21}$ The HeLD-Th was tested for content validity by an expert panel that showed an appropriate item objective congruence index (IOC) value of $0.76 .^{21}$ Regarding reliability testing, we established a pilot study among 30 older adults from Yaring district, a nearby community; the HeLD-Th 
produced acceptable internal consistency with a total Cronbach alpha coefficient of 0.945 .

Information regarding sociodemographic and oral health-related behaviors was obtained by a modified selfreported questionnaire from the 8th Thailand Oral Health Survey 2017 (Th-OHS). ${ }^{16}$ Sociodemographic data were as follows: age ( $\leq 74$ years/>74 years), sex (male/female), marital status (married/other), educational level ( $\leq$ primary school/> primary school), monthly income $(<15,000$ BAHT $(\$ 475) / \geq 15,000$ BAHT). Oral health-related behavior data: toothbrushing frequency $(<$ twice daily $>$ twice daily), toothbrushing duration $(<2$ minutes $/>2$ minutes $)$, and regular dental visit (yes/no).

\section{Outcome Variable}

Number of remaining teeth (NRT)

A trained examiner evaluated the NRT based on the Th-OHS criteria. ${ }^{16}$ The examiner took a comprehensive approach for assessing dental status. A trained assistant recorded the data in sequence from one tooth to the nearby tooth or edentulous area; a permanent tooth was counted as the remaining tooth when the whole part of the dental crown was visible. ${ }^{16}$ When the crown was destroyed or only the root remained, the tooth was considered absent since it would not have masticatory function.

\section{Data Collection}

The NRT data were obtained from clinical examinations by a dentist (the first author), who was trained to be an examiner following the Th-OHS criteria. ${ }^{16}$ The intraexaminer consistency of the Kappa statistic was $85 \%$. The trained interviewers gathered sociodemographic, oral health-related behaviors, and OHL data through face-toface interviews. The feasibility of the questionnaires was tested in advance by conducting a pilot test among older adults from nearby districts.

\section{Data Analysis}

Data analysis was performed using the SPSS program (version 22; SPSS, Inc., an IBM Company, Chicago, IL, USA). The Shapiro-Wilk test was used for normality testing. All continuous variables were not normally distributed. The Mann-Whitney $U$-test, chi-square test and binary logistic regression analysis were used. A multivariate logistic regression model was developed to test the associations between OHL and NRT and other potential covariates. All analyses were two-sided with a 95\% confidence interval.

\section{Results}

A total of 365 older adults met the inclusion criteria and were enrolled in the screening phase; four refused to participate because of a lack of time and did not want to be a research participant. A total of 361 older adults were included in this study.

Table 1 shows that the study participants aged 60-94 years (mean age $71.63 \pm 6.76$ ) were generally independent-living (mean Thai Barthel ADL Index was $19.35 \pm 1.71$ ) and had an average NRT of $9.99 \pm 9.16$ teeth. A total of $50.7 \%$ of the study participants had high OHL with a median HeLD-Th score of 37; we then used this number (37) to categorize the study subjects into low OHL and high OHL groups. Participants who had HeLD-Th scores $<37$ indicated low OHL, and those with HeLD-Th scores $\geq 37$ were categorized as high OHL. The majority of the study participants had fewer than 20 residual teeth $(79.5 \%)$. The main sociodemographic features were female sex $(72.9 \%)$, age $\leq 74$ years $(65.9 \%)$, marital status $(65.9 \%)$, low schooling $(77.6 \%)$, and salary below 15,000 BAHT ( $\$ 475)$ per month $(89.5 \%)$. With regard to oral health-related habits, most of the participants had toothbrushing frequency $\geq$ twice daily $(72.9 \%)$ and toothbrushing duration $\geq 2$ minutes (61.8\%). Surprisingly, although $100 \%$ of participants had universal health coverage insurance (UHC), they did not have regular dental visits (90.3\%).

Analyses with the Mann-Whitney $U$-test (Table 2) indicated that participants with high OHL had more remaining teeth and were younger than those with limited OHL $(P<0.001)$. Chi-square analyses showed significant relationships between OHL and NRT $(P=0.003)$, age $(P=0.001)$, educational level $(P<0.001)$, monthly income $(P=0.001)$, frequency of toothbrushing $(P=0.006)$, duration of toothbrushing $(P=0.003)$ and regular dental visits $(P=0.026)$.

Table 3 demonstrates binary logistic regression analyses. In the unadjusted model, there were strong associations between OHL and NRT $(P=0.003)$, age $(P=0.001)$, educational level $(P<0.001)$, income $(P=0.001)$, frequency of toothbrushing $(P=0.006)$, time of toothbrushing $(P=0.003)$, and regular dental treatment $(P=0.029)$. In the adjusted models, significant associations of OHL remained for NRT (odds ratio $[\mathrm{OR}]=1.986, P=0.018)$, age $(\mathrm{OR}=1.743$, $P=0.023)$, and educational level $(\mathrm{OR}=2.365, P=0.007)$.

\section{Discussion}

This study reports the relationship between OHL and NRT among Thai elderly individuals. Binary logistic regression analysis proved that there were significant associations 
Table I General Study Participant Characteristics ( $=36 \mathrm{I})$

\begin{tabular}{|c|c|c|}
\hline Continuous Variables & Mean \pm SD & Median (Min-Max) \\
\hline ADL scores & $|9.35 \pm 1.7|$ & $20.00(2-20)$ \\
\hline HeLD-Th scores & $36.32 \pm 10.69$ & $37.00(0-56)$ \\
\hline Age (years) & $71.63 \pm 6.76$ & $71.00(60-94)$ \\
\hline Number of remaining teeth & $9.99 \pm 9.16$ & $8.00(0-32)$ \\
\hline Categorical Variables & Number & $\%$ \\
\hline \multicolumn{3}{|l|}{$\begin{array}{l}\text { Oral Health Literacy } \\
(\mathrm{OHL})\end{array}$} \\
\hline High OHL $\geq 37$ & 183 & 50.7 \\
\hline Low $\mathrm{OHL}<37$ & 178 & 49.3 \\
\hline \multicolumn{3}{|l|}{$\begin{array}{l}\text { Number of remaining teeth } \\
\text { (NRT) }\end{array}$} \\
\hline NRT $\geq 20$ teeth & 74 & 20.5 \\
\hline NRT $<20$ teeth & 287 & 79.5 \\
\hline \multicolumn{3}{|l|}{ Age: years } \\
\hline Age $\leq 74$ & 238 & 65.9 \\
\hline Age $>74$ & 123 & 34.1 \\
\hline \multicolumn{3}{|l|}{ Sex: } \\
\hline Female & 263 & 72.9 \\
\hline Male & 98 & 27.1 \\
\hline \multicolumn{3}{|l|}{ Marital status } \\
\hline Married & 238 & 65.9 \\
\hline Others & 123 & 34.1 \\
\hline \multicolumn{3}{|l|}{ Educational level } \\
\hline$>$ Primary education & 81 & 22.4 \\
\hline$\leq$ Primary education & 280 & 77.6 \\
\hline \multicolumn{3}{|l|}{ Income per month } \\
\hline$\geq 15,000$ BAHT $(\$ 475)$ & 38 & 10.5 \\
\hline$<15,000$ BAHT & 323 & 89.5 \\
\hline \multicolumn{3}{|l|}{ Toothbrushing frequency } \\
\hline$\geq$ twice daily & 263 & 72.9 \\
\hline$<$ twice daily & 98 & 27.1 \\
\hline \multicolumn{3}{|l|}{ Toothbrushing duration } \\
\hline$\geq 2$ minutes & 223 & 61.8 \\
\hline$<2$ minutes & 138 & 38.2 \\
\hline \multicolumn{3}{|l|}{ Routine dental care } \\
\hline Yes & 35 & 9.7 \\
\hline No & 326 & 90.3 \\
\hline $\begin{array}{l}\text { Government health } \\
\text { insurance (UHC) }\end{array}$ & 361 & 100 \\
\hline
\end{tabular}

Abbreviations: SD, standard deviation; Min, minimum; Max, maximum; ADL, Thai Barthel Activities of Daily Living index; OHL, oral health literacy; NRT, number of remaining teeth; HeLD-Th, Thai version of Health Literacy in Dentistry questionnaire; UHC, universal health coverage scheme.
Table 2 Factors Associated with Oral Health Literacy of the Study Participants $(\mathrm{N}=36 \mathrm{I})$

\begin{tabular}{|c|c|c|c|}
\hline \multirow[t]{3}{*}{ Variables } & \multicolumn{2}{|c|}{$\begin{array}{c}\text { Oral Health Literacy } \\
\text { Levels }\end{array}$} & \\
\hline & High OHL & Low OHL & \\
\hline & $\begin{array}{l}\text { HeLD-Th } \\
\quad \geq 37\end{array}$ & $\begin{array}{l}\text { HeLD-Th } \\
\quad<37\end{array}$ & \\
\hline \multicolumn{3}{|c|}{ Continuous Variables, Median (Min-Max) } & $P$-value ${ }^{a}$ \\
\hline $\begin{array}{l}\text { Number of remaining } \\
\text { teeth (NRT) } \\
\text { Age (Years) }\end{array}$ & $\begin{array}{l}10(0-32) \\
70(60-89)\end{array}$ & $\begin{array}{c}6(0-31) \\
72(60-94)\end{array}$ & $\begin{array}{l}<0.001 \\
<0.001\end{array}$ \\
\hline \multicolumn{3}{|c|}{ Categorical Variables, Number (\%) } & $P$-value ${ }^{b}$ \\
\hline $\begin{array}{l}\text { Number of remaining } \\
\text { teeth }(N R T) \\
\qquad N R T \geq 20 \text { teeth } \\
\text { NRT }<20 \text { teeth }\end{array}$ & $\begin{array}{l}49(66.2) \\
134(46.7)\end{array}$ & $\begin{array}{l}25(33.8) \\
153(53.3)\end{array}$ & 0.003 \\
\hline $\begin{array}{l}\text { Age: } \\
\qquad \begin{array}{l}\text { Age } \leq 74 \\
\text { Age }>74\end{array}\end{array}$ & $\begin{array}{l}\text { I } 36(57.1) \\
47(38.2)\end{array}$ & $\begin{array}{l}102(42.9) \\
76(61.8)\end{array}$ & 0.001 \\
\hline $\begin{array}{l}\text { Sex } \\
\text { Female } \\
\text { Male }\end{array}$ & $\begin{array}{l}126(47.9) \\
57(58.2)\end{array}$ & $\begin{array}{l}\mid 37(52.1) \\
4 \mid(4 \mid .8)\end{array}$ & 0.083 \\
\hline $\begin{array}{c}\text { Marital status } \\
\text { Married } \\
\text { Others }\end{array}$ & $\begin{array}{l}127(53.4) \\
56(45.5)\end{array}$ & $\begin{array}{l}\text { III (46.6) } \\
67(54.5)\end{array}$ & 0.158 \\
\hline $\begin{array}{l}\text { Educational level } \\
>\text { Primary education } \\
\quad \leq \text { Primary education }\end{array}$ & $\begin{array}{l}60(74.1) \\
123(43.9)\end{array}$ & $\begin{array}{l}21(25.9) \\
157(56.1)\end{array}$ & $<0.001$ \\
\hline $\begin{array}{l}\text { Income per month } \\
\geq 15,000 \text { BAHT } \\
(\$ 475) \\
\quad<15,000 \text { BAHT }\end{array}$ & $\begin{array}{l}29(76.3) \\
154(47.7)\end{array}$ & $\begin{array}{l}9(23.7) \\
169(52.3)\end{array}$ & 0.001 \\
\hline $\begin{array}{l}\text { Toothbrushing } \\
\text { frequency } \\
\quad \geq \text { twice daily } \\
<\text { twice daily }\end{array}$ & $\begin{array}{l}145(55.1) \\
38(38.8)\end{array}$ & $\begin{array}{l}118(44.9) \\
60(61.2)\end{array}$ & 0.006 \\
\hline $\begin{array}{l}\text { Toothbrushing duration } \\
\quad \geq 2 \text { minutes } \\
<2 \text { minutes }\end{array}$ & $\begin{array}{l}\text { I } 27(57.0) \\
56(40.6)\end{array}$ & $\begin{array}{l}96(43.0) \\
82(59.4)\end{array}$ & 0.003 \\
\hline $\begin{array}{l}\text { Routine dental care } \\
\text { Yes } \\
\text { No }\end{array}$ & $\begin{array}{c}24(68.6) \\
159(48.8)\end{array}$ & $\begin{array}{l}11(31.4) \\
167(51.2)\end{array}$ & 0.026 \\
\hline
\end{tabular}

Notes: ${ }^{a}$-value from the Mann-Whitney $U$-test. ${ }^{b} P$-value from the Chi-Square test. Abbreviations: $\mathrm{OHL}$, oral health literacy; NRT, number of remaining teeth; HeLD-Th, Thai version of Health Literacy in Dentistry questionnaire; Min, minimum; Max, maximum. 
Table 3 Simple Bivariate and Multivariate Binary Logistic Regression Analyses of Oral Health Literacy Levels of Participants

\begin{tabular}{|c|c|c|c|c|}
\hline Variables & Unadjusted OR (95\% CI) & $P$-value ${ }^{a}$ & Adjusted OR $(95 \% \mathrm{Cl})$ & $P$-value ${ }^{b}$ \\
\hline Number of remaining teeth (NRT) & & 0.003 & & 0.018 \\
\hline NRT $\geq 20$ teeth & I & & 1 & \\
\hline NRT $<20$ teeth & $2.238(1.311-3.820)$ & & $1.986(1.123-3.512)$ & \\
\hline Age & & 0.001 & & 0.023 \\
\hline Age $\leq 74$ & I & & $\mathrm{I}$ & \\
\hline Age $>74$ & $2.156(1.38 I-3.365)$ & & $1.743(1.079-2.814)$ & \\
\hline Sex & & 0.084 & & 0.084 \\
\hline Female & I & & I & \\
\hline Male & $0.662(0.4 \mid 4-1.057)$ & & $0.627(0.369-1.065)$ & \\
\hline Marital status & & 0.159 & & 0.685 \\
\hline Married & I & & I & \\
\hline Others & $1.369(0.884-2.119)$ & & $0.903(0.552-1.478)$ & \\
\hline Educational level & & $<0.001$ & & 0.007 \\
\hline$>$ Primary education & I & & I & \\
\hline$\leq$ Primary education & $3.647(2.104-6.322)$ & & $2.365(1.272-4.398)$ & \\
\hline Income per month & & 0.001 & & 0.191 \\
\hline$\geq 15,000$ BAHT $(\$ 475)$ & 1 & & I & \\
\hline$<15,000$ BAHT & $3.536(1.622-7.707)$ & & $1.795(0.746-4.320)$ & \\
\hline Toothbrushing frequency & & 0.006 & & 0.228 \\
\hline$\geq$ twice daily & I & & I & \\
\hline$<$ twice daily & $1.940(1.208-3.115)$ & & $1.412(0.806-2.474)$ & \\
\hline Toothbrushing duration & & 0.003 & & 0.160 \\
\hline$\geq 2$ minutes & I & & I & \\
\hline$<2$ minutes & $1.937(1.259-2.98 \mathrm{I})$ & & $1.435(0.867-2.376)$ & \\
\hline Routine dental care & & 0.029 & & 0.225 \\
\hline Yes & I & & I & \\
\hline No & $2.292(1.087-4.832)$ & & $1.660(0.732-3.762)$ & \\
\hline
\end{tabular}

Notes: ${ }^{a} P$-value from univariate binary logistic regression. ${ }^{b} P$-value from multivariate binary logistic regression.

Abbreviations: OR, odds ratio; $\mathrm{Cl}$, confidence interval; NRT, number of remaining teeth.

between low OHL and lower NRT, older age, and lower educational level.

The findings indicated that the study participants who had low OHL were nearly two times more likely to have fewer than 20 remaining teeth $(P=0.018)$. This result was consistent with several previous studies, which indicated that limited OHL leads to poorer oral health status and tooth loss. ${ }^{4-6}$ In this study, $66.2 \%$ of participants with more than 20 remaining teeth had high OHL. Lower OHL may be an indicator for lower levels of daily oral health practices for this population..$^{7-9}$ Our study also found that in the low OHL group, $61.2 \%$ of participants had improper toothbrushing frequency, $59.4 \%$ had insufficient toothbrushing duration, and 51.2\% had irregular dental attendance. A previous study in Kuwait confirmed that people with limited OHL more often had postponed dental care, resulting in a higher number of missing teeth. ${ }^{4}$

In the present study, the older samples were almost 1.7 times more likely to have low OHL $(P=0.023)$. We found that $61.8 \%$ of participants aged more than 74 years had low OHL. Similar findings have been reported in several studies: in Kuwait, ${ }^{4}$ the United States (US), ${ }^{7}$ and Thailand ${ }^{8,21}$ lower OHL was identified more commonly among older individuals than younger individuals. A few studies in the United States concluded that inadequate OHL was considered an obstacle for better oral health status and induced oral health inequality. ${ }^{19,20}$ Therefore, increasing OHL is a key to enhancing the quality of oral hygiene, proper oral health-related habits, and satisfaction with oral health, which leads to healthier oral health status in the elderly. ${ }^{9,10}$ 
In this study, participants with low OHL were nearly 2.3 times more likely to have lower education levels $(P=$ 0.007 ), and $74.1 \%$ of educated participants had higher OHL scores. Similarly, various studies have reported significant associations between OHL and educational levels. ${ }^{4,7}$ A study in Kuwait reported that lower levels of education were related to a more limited OHL status. ${ }^{4}$ A study in the US revealed that educated persons had better OHL scores than those who responded to lower education. $^{7}$ This study is advanced because most of the research in this field has been conducted using tools based only on word recognition tests, which do not measure all the constructs involved in oral health literacy, unlike the HeLD-Th, which is a more complete tool.

\section{Limitations}

Although this research may have indicated a significant association between OHL and NRT among Thai elderly individuals, it still has certain limitations. This study used self-reported questionnaires among older adults, which are subject to some limitations, such as bias by the participant's exaggeration or forgetting some relevant details. Additionally, the findings were estimated for a small sample of older adults in a community, and $100 \%$ of participants had universal health coverage insurance. Thus, generalizations should be considered. Future research on OHL and dental caries, gingival health, oral lesions, and root caries among a large sample size should be recommended.

\section{Conclusions}

The study findings indicated significant differences between OHL and NRT. NRT is a final oral health outcome for the elderly population. The significance of this evidence is that OHL influences NRT among older Thai adults who have lower education levels. Therefore, OHL intervention is an essential strategy for better oral healthrelated behaviors to reduce tooth loss and to improve oral health status among older Thai adults.

\section{Acknowledgments}

We would like to thank all the older people who participated in this study. We also thank all the health care providers at Panare Hospital.

\section{Funding}

This research is funded by Chulalongkorn University CU_GR_63_12_32_05 (Ratchadaphiseksomphot Endow ment Fund).

\section{Disclosure}

The authors report no conflicts of interest pertaining to this work.

\section{References}

1. Baur CE, Comings JP, Evans C. The invisible barrier: literacy and its relationship with oral health. $J$ Public Health Dent. 2005;65:174-182. doi:10.1111/j.1752-7325.2005.tb02808.x

2. Jones K, Brennan D, Parker E, Jamieson L. Development of a short-form Health Literacy Dental Scale (HeLD-14). Community Dent Oral Epidemiol. 2015;43(2):143-151. doi:10.1111/cdoe.12133

3. Jones K, Parker E, Mills H, Brennan D, Jamieson LM. Development and psychometric validation of a Health Literacy in Dentistry scale (HeLD). Community Dent Health. 2014;31:37-43.

4. Baskaradoss JK. Relationship between oral health literacy and oral health status. BMC Oral Health. 2018;18(1):18. doi:10.1186/s12903018-0640-1

5. Batista MJ, Lawrence HP. Sousa MDLRD. Oral health literacy and oral health outcomes in an adult population in Brazil. BMC Public Health. 2018;18:1-9.

6. Mohammadi TM, Malekmohammadi M, Hajizamani HR, Mahani SA. Oral health literacy and its determinants among adults in Southeast Iran. Eur J Dent. 2018;12(03):439-442. doi:10.4103/ejd. ejd_429_17

7. Messadi DV, Macek MD, Markovic D, Atchison KA. Oral health literacy, preventive behavior measures, and chronic medical conditions. JDR Clin Translat Res. 2018;3(3):288-301. doi:10.1177/ 2380084418769835

8. Piyakhunakorn P, Sermsuti-Anuwat N. The associations between oral health literacy and oral health-related behaviours among community-dwelling older people in Thailand. Glob J Health Sci. 2021;13(3):1-7. doi:10.5539/gjhs.v13n3p1

9. Hjertstedt J, Barnes SL, Sjostedt JM. Investigating the impact of a community-based geriatric dentistry rotation on oral health literacy and oral hygiene of older adults. Gerodontology. 2014;31 (4):296-307. doi:10.1111/ger.12038

10. Tenani CF, De Checchi MHR, Bado FMR, Ju X, Jamieson L, Mialhe FL. Influence of oral health literacy on dissatisfaction with oral health among older people. Gerodontology. 2020;37:46-52. doi:10.1111/ger.12443

11. Kickbusch I, Pelikan JM, Apfel F, Tsouros AD Health literacy. The solid facts; 2013. Available from: https://apps.who.int/iris/bitstream/ handle/10665/128703/e96854.pdf. Accessed November 10, 2020.

12. Wehmeyer MMH, Corwin CL, Guthmiller JM, Lee JY. The impact of oral health literacy on periodontal health status. J Public Health Dent. 2014;74:80-87. doi:10.1111/j.1752-7325.2012.00375.x

13. Holtzman JS, Atchison KA, Macek MD, Markovic D. Oral health literacy and measures of periodontal disease. $J$ Periodontol. 2017;88:78-88. doi:10.1902/jop.2016.160203

14. Emami E, De Souza RF, Kabawat M, Feine JS. The impact of edentulism on oral and general health. Int J Dent. 2013;2013:1-7. doi:10.1155/2013/498305

15. Fantin R, Delpierre C, Kelly-Irving M, Barboza Solís C. Early socioeconomic conditions and severe tooth loss in middle-aged Costa Ricans. Community Dent Oral Epidemiol. 2018;46:178-184. doi:10.1111/cdoe.12351

16. Ministry of Public Health. National Oral Health Survey of Thailand; 2017. Available from: http://www.dent.chula.ac.th/upload/news/791/ file_1_5834.pdf. Accessed November 10, 2020.

17. Da Silva DD, Rihs LB, Da Luz Rosário De Sousa M. Factors associated with remaining teeth of older adults in the state of São Paulo, Brazil, 2002. Gerodontology. 2020;37(3):288-296. doi:10.1111/j.1741-2358.2008.00257.x 
18. Pan M-Y, Hsieh T-C, Tai H-C, Lin M-S, Lin Y-C, Chen M-Y Prevalence of and factors associated with fewer than 20 remaining teeth in Taiwanese adults with disabilities: a community-based cross-sectional study. BMJ Open. 2017;7(10):e016270. doi:10.1136/ bmjopen-2017-016270

19. Horowitz AM, Kleinman DV. Oral health literacy: the new imperative to better oral health. Dent Clin North Am. 2008;52(2):333-344. doi:10.1016/j.cden.2007.12.001

20. Horowitz AM, Kleinman DV. Oral health literacy: a pathway to reducing oral health disparities in Maryland. $J$ Public Health Dent. 2012;72:S26-30. doi:10.1111/j.1752-7325.2012.00316.x
21. Sermsuti-Anuwat N, Pongpanich S. Validation of Thai version of the Health Literacy in Dentistry scale: validation among Thai adults with physical disabilities. $J$ Investig Clin Dent. 2019;10(4):10. doi:10.1111/jicd.12474

22. Ministry of Public Health. Thai Barthel Activities of Daily Living (ADL) index. Available from: http://www.thethaicancer.com/PDF/ Drug/OCPAForm/Barthel\%20ADL_2561.pdf. Accessed November 10, 2020.

\section{Publish your work in this journal}

Clinical, Cosmetic and Investigational Dentistry is an international, peer-reviewed, open access, online journal focusing on the latest clinical and experimental research in dentistry with specific emphasis on cosmetic interventions. Innovative developments in dental materials, techniques and devices that improve outcomes and patient satisfaction and preference will be highlighted. The manuscript management system is completely online and includes a very quick and fair peer-review system, which is all easy to use. Visit http://www.dovepress.com/testimonials.php to read real quotes from published authors. 